\title{
Trust: from the Philosophical to the Commercial
}

\author{
Jonathan Tallant $^{1}$ (D) $\cdot$ Donatella Donati $^{2}$
}

Published online: 6 February 2019

(C) The Author(s) 2019

\begin{abstract}
This is a paper about trust, with a specific focus on the ways in which trust is investigated in the business literature and the commercial sector. The lens through which the topic is approached is distinctively philosophical. We use philosophical tools to demonstrate the paucity of some of the accounts of trust that are given in the business and management literature, as well as the empirically informed literature that has flowed from them. We close with a discussion of some work on trust drawn from the commercial sector that would, as we shall demonstrate, benefit from a clearer understanding of the nature of trust. We take this to be important. Trust is a key moral and ethical component of transactional relationships. Without a clear understanding of the notion, we will be missing a central concept in our attempts to understand the commercial world that we inhabit. The paper proceeds in four parts. In the first part of the paper we introduce some reasonably standard philosophical distinctions between different kinds of trust, as well as saying a little more about our methods. In the second, we demonstrate that a reasonably widely held account of trust in the business and management literature fails to capture the nuance reflected by the philosophical literature. On the basis of this, in the third section, we suggest that various pieces of empirical work require reassessment. In the final part of the paper we explore some non-academic discussions of trust drawn from the commercial sector arguing that, there too, we require a more precise understanding of trust. In short, though, our overarching argument is simply this: if we can give a more precise analysis of trust, it follows that both our empirical research and current commercial activity can be improved.
\end{abstract}

Keywords Trust $\cdot$ Business $\cdot$ Philosophy $\cdot$ Commercial

Jonathan Tallant

jonathan.tallant@nottingham.ac.uk

Donatella Donati

donatella.donati87@gmail.com

1 Department of Philosophy, University of Nottingham, Nottingham NG7 2RD, UK

2 Department of Philosophy, University of L'Aquilia, L'Aquila, Italy 


\section{Introduction}

This is a paper about trust, with a specific focus on the ways in which trust is investigated in the business literature and the commercial sector. The lens through which the topic is approached is distinctively philosophical. We use philosophical tools to demonstrate the paucity of some of the accounts of trust that are given in the business and management literature, as well as the empirically informed literature that has flowed from them.

The paper proceeds in four parts. In the first part of the paper we introduce some reasonably standard philosophical distinctions between different kinds of trust, as well as saying a little more about our methods. In the second, we demonstrate that some reasonably widely held accounts of trust in the business and management literature fail to capture the nuance reflected by the philosophical literature, through the use of counterexamples. On the basis of this, in the third section, we suggest that various pieces of empirical work require re-assessment. In the final part of the paper we explore some non-academic discussions of trust drawn from the commercial sector arguing that, there too, we require a more precise understanding of trust. In short, though, our overarching argument is simply this: if we can give a more precise analysis of trust, it follows that both our empirical research and current commercial activity can be improved. We take this to be important. Trust is a key moral and ethical component of transactional relationships. Without a clear understanding of the notion, we will be missing a central concept in our attempts to understand the commercial world that we inhabit.

\section{Trust in Philosophy}

In this section we deploy standard philosophical tools to demonstrate that there are a range of closely related concepts, all of which are related to trust. Primarily, we deploy the methods of conceptual analysis, counter example and simply carefully teasing apart different concepts. All tools are well established within the philosophical toolkit.

Roughly, conceptual analysis requires that we first clarify a target concept and then seek to fully analyse the target concept in terms of related concepts. ${ }^{1}$ We can illustrate with the case of knowledge. An attempted analysis might treat knowledge as justified, true belief and say that when, and only when, a subject has a justified, true belief that $p$ is the case, the subject knows that $p$. If we can find a counter example - a case where it is plausible to think that the subject knows that $p$, but does not have a justified true belief that $p$, or else has a justified true belief that $p$, but does not know that $p$, then our analysis will have failed. ${ }^{2}$ This is how conceptual analysis and counter example proceeds. We will proceed in the same way, but we will consider the notion of trust. We will suggest that some key accounts of trust in the business and management literature are prone to counter examples and that this generates a problem.

Many of the examples and counterexamples that we borrow from the philosophical literature are drawn from everyday life, rather than the business or commercial world. Nonetheless, where we do provide such examples as they are drawn from the philosophical literature we typically also deploy an example from business in order to demonstrate the applicability of the general point.

\footnotetext{
${ }^{1}$ For an extensive discussion and defence of conceptual analysis, see Jackson (1999).

${ }^{2}$ Most agree that it does fail. See, e.g., Steup (2018: section 1).
} 
In the case of trust, we should begin, however, by clarifying a target concept. There are many closely related concepts and they need carefully teasing apart. It is plausible to think that at least three main notions associated with trust have been identified in the wider philosophical canon. First we find what we will call an attitude of trust. This is represented via a two-placed predicate such that 'x trusts y' (cf. Faulkner 2015: 16). Example: Tasha trusts Marvin.

Second, an agent, $\mathrm{x}$, may trust another agent, $\mathrm{y}$, to perform some action, $\varphi$ : $\mathrm{x}$ trusts $\mathrm{y}$ to $\varphi$. Call this 'contractual trust'. 'Contractual trust' is a three-place term, connecting two agents to some action. Example: Tasha Trusts Marvin to complete the company tax return on time. The third main notion associated with trust is trustworthiness in general. 'Trustworthiness' is a oneplaced predicate. Example: Tasha is trustworthy. ${ }^{3}$ Rather than treat trustworthiness itself as a kind of trust, it seems more appropriate to see it as an epistemic virtue; something like the feature in virtue of which trusting some agent is justified or appropriate. For our current purposes, this is fine. We simply want to have the different concepts on the table.

These notions (plausibly) come apart. To illustrate: we may not trust a particular individual or company, despite the fact that we do trust them to carry out particular tasks. A reasonable example, here, might be financial institutions. Following the 2008 financial crisis, we might think that banks were not typically trusted. Nonetheless, since the vast majority of banks remained solvent, it is reasonable to infer that customers still trusted the banks to look after their savings. These distinctions are, we think, fairly standard within the philosophical literature. $^{4}$

Within that literature, it is also typical to see a further distinction drawn between trust as 'mere reliance' and a richer, morally loaded notion of trust. We demonstrate this notion via the following from Hawley (2014: 2):

we often rely upon inanimate objects but we do not grant them the rich trust we sometimes grant one another; inanimate objects can be reliable but not genuinely trustworthy. Moreover our reactions to misplaced trust differ from our reactions to misplaced reliance. Suppose I trust you to look after a precious glass vase, yet you carelessly break it. I may feel betrayed and angry; recriminations will be in order; I may demand an apology. Suppose instead that I rely on a shelf to support the vase, yet the shelf collapses, breaking the vase. I will be disappointed, perhaps upset, but it would be inappropriate to feel betrayed by the shelf, or to demand an apology from it.

Thus, let us say that we have 'mere reliance' in cases where there is no trust in the moral sense of the word. We 'trust a ladder to hold our weight'; 'trust the shelf to hold the books'. This is nothing more than reliance. From here on, where trust carries with it a moral commitment, we shall speak simply of 'trust': 'I trust you to look after my cat', 'you can trust Tim; he is good for it'. Otherwise we shall speak of reliance.

Last, but by no means least, we must also mention distrust. Importantly, distrust is not to be identified with the mere absence of trust. To illustrate, when first introduced to someone it is

\footnotetext{
3 Jones (2012: 70-1) makes the case that matters are, in fact, more complex.

$\mathrm{B}$ is trustworthy with respect to A in do-main of interaction $\mathrm{D}$, if and only if she is competent with respect to that domain, and she would take the fact that $\mathrm{A}$ is counting on her, were A to do so in this domain, to be a compelling reason for acting as counted on.

Nothing will turn on this, however. For further discussion of trustworthiness see, e.g., Hardin (2002).

${ }^{4}$ Our discussion here is heavily influenced by Faulkner (2015) with whom we find ourselves in complete agreement on these issues.
} 
highly unlikely that we will instantly trust them. It is similarly unlikely that we will instantly distrust them. Rather, at the point of first meeting them we will neither trust nor distrust our new interlocutor. It seems, then, that our distrust requires not merely that we not trust, but that we actively hold a position of distrust. Similarly, in a commercial setting, a startup company may suffer from a trust deficit. No-one yet trusts them to deliver. But that is quite different from saying that they are distrusted to deliver. Such distrust will likely have to be earned in some way, either by poor performance or immoral behavior. Similar remarks go for trust.

Whilst this concludes our project of teasing apart some of the different notions of trust and distrust discussed in the philosophical literature, it will also be useful to delve a little further into the philosophical work that has been done on trust. For, as well as teasing apart these different kinds of trust, philosophers writing on this topic have also sought to provide analyses of these notions. This will serve to give the reader a sense of the shape of some of these philosophical accounts, though since they are not a focus we shall not say too much about them.

For instance, building on and refining Hawley's account of contractual trust and distrust, Tallant (2017) provides the following accounts of trust (2017: 265) and distrust (2017: 264).

To trust someone to do something is to believe that she has a commitment to doing it, and: to either rely upon her to meet that commitment, or, if they are not called upon to meet that commitment, to believe that they could be relied upon to meet that commitment, if so called upon.

To distrust someone to do something is to believe that she has a commitment to doing it, and yet not rely upon her to meet that commitment because of reservations about whether or not they can be relied upon to do it.

This is intended to provide an analysis of contractual trust (in the rich, moral sense). So, suppose that we imagine that Amal trusts Marcus to carry out the delivery of important components to a customer. If Tallant's analysis is correct, then this amounts to the claim that Amal believes that Marcus has a commitment to delivering important components to a customer and that she can either rely upon him to do so, or else believes that he could be relied upon where she to call upon him to do so.

Similarly, if she distrusts Marcus to deliver the components, Amal must believe that he has a commitment to delivering them, yet she will not rely upon him to do so because she has reservations about his reliability.

\section{Trust in the Management Literature}

The business and management literature with which we are here engaged does not recognise many of the distinctions described in the previous section. For instance, in a significant number of discussions of trust in the business literature, there is no distinction drawn between trustworthiness, contractual trust and the two-placed trust (what we described as the 'attitude of trust') that we mentioned earlier. Further, and more pressingly for our current purposes, the accounts of trust that are offered are, we think, lacking. In what follows we consider some prominent examples. We cannot claim to be exhaustive; the literature is simply too large for us to be wholly confident in that judgement. Nonetheless, we positions that we discuss here are prominent, significant and fairly representative of the field. 


\section{Mayer et al.}

Though there is no firmly agreed and explicit definition within the business literature, a fairly widely adopted approach is that advocated by Mayer et al. (1995: 712):

'Trust is the willingness to be vulnerable to the actions of another party based on the expectation that the other will perform a particular action important to the trustor, irrespective of the ability to monitor or control that other party'.

We do not mean to be exhaustive, and the reader is welcome to pursue the matter for themselves, but Mayer's definition is adopted as the preferred account of trust in a very wide range of papers, including, just to give some representative citations: Hassanein and Head (2007), Kim et al. 2008, Hwee Hoon and Lim (2009), Li and Yung-Shao Yeh (2010), Colquitt and Rodell (2011), Lin (2011), Brattström et al. (2012), Abosag and Lee (2013), Lankton and D. McKnight H. (2012), Fang et al. (2014), Allen et al. (2015), Vanhala et al. (2016), and Fletcher and Sora (2017).

Given our reflections on the different kinds of trust, mentioned in section 2, it behooves us to ask which kind of trust is being identified here by Mayer et al.

We do not think that it can be trustworthiness. The analysis is obviously of the wrong kind. To spell out the point, we swap 'trustworthiness' in for 'trust' in Mayer et al's account. The resulting analysis would be obviously wrong. It would read: 'Trustworthiness is the willingness to be vulnerable to the actions of another party based on the expectation that the other will perform a particular action important to the trustor, irrespective of the ability to monitor or control that other party.' Trustworthiness is no such thing. Trustworthiness is a trait that seemingly allows others to be willing to be vulnerable. This putative analysis would simply get that wrong. That being so, we do not think that this can be what Mayer et al. intend.

We also do not think that the analysis can be of trust as a two-placed term, such that one person trusts another. In the analysis provided, there is explicit mention of an expectation that $a$ particular action will be performed. That seems out of step with the general idea of trust as a two-placed term. Above we made the point that someone can be trusted, despite the fact that we do not trust them to perform a particular action. A similar point cuts in the other direction. If we trust someone, it is not merely that we expect that they will perform $a$ particular action that is important to us. If we were to say that we 'trust Xyianthipe', we do not take that to mean that there is a particular action that we expect her to perform, or that we are relying upon her to perform. ${ }^{5}$ Rather, by saying that we 'trust Xyianthipe' we mean to signal something far stronger (perhaps that, in a range of cases, presumably of some significance, we think that Xyianthipe can be trusted to perform the desired action.)

That being so, this leaves us with only contractual trust that Mayer et al could be examining. We note here, however, that Mayer et al's account ought not to be treated as an analysis of contractual trust either as it is prone to counter examples; cases where contractual trust does not occur even though Mayer et al's analysis is satisfied. Indeed, a fairly standard kind of example, one that we borrow from Hawley (2014: 2), will do the job.

\footnotetext{
${ }^{5}$ Nor need we be saying that they are 'trustworthy'. We can recognise that someone is trustworthy, without actually coming to trust them. As in 'I know that they are re trustworthy-I can see that. For whatever reason, though, I just cannot bring myself to trust them.'
} 
Suppose you regularly bring too much lunch to work, and leave the excess for others to eat. Suppose you do this because you're bad at judging quantities, not because you're keen to feed your colleagues. I rely on you to provide my lunch: I anticipate that you will do so, and I don't make alternative arrangements. But this reliance should not amount to trust: you would owe me no apology if you ate all the food yourself, and I ought not to feel betrayed by this, even if I felt disappointed (and hungry).

In this imagined case, Hawley is described as willing to make herself vulnerable (to potential hunger) by the actions of another party (the regular lunch-bringer) based on the expectation that said party (the regular lunch-bringer) will bring lunch-something that is important to Hawley. In the case described, Hawley is unable to monitor or control that the regular lunch bringer will bring lunch the next day.

To see that similar cases can be constructed within the business sphere, we present the following: suppose that company $\mathrm{C}$ regularly, mistakenly, and contradicting their own statements of what is 'in the box', ship their mobile phones with cases - that are described in all promotional materials as to be purchased separately. The company does this because its production line is a mess, not because it is keen to provide the cases to customers. A buyer, aware of this, might rely upon the company to provide them with a phone and case, without making an additional purchase of a case. In other words, they anticipate the case being shipped and make no alternative arrangements to get hold of one. This reliance should not amount to trust: the company would owe the buyer no apology if the phone turned up without a case, and the buyer ought not to feel betrayed by this, even if they felt disappointed.

Nonetheless, and as Hawley notes in the quotation, this reliance upon the other party does not constitute trust. Whilst Hawley may be relying on the imagined lunch bringer to provide lunch, this does not seem to be a case where Hawley can be said to trust. One way to bring this out is to notice that nothing morally blameworthy is done if no lunch is brought 1 day. Per the above, where we trust someone to perform an action, and that trust is broken, we would expect to find moral blameworthiness.

Since, as we have just seen, the account of trust provided by Mayer et al would describe this as a case of trust, Mayer et al's analysis fails if it is to be read as an analysis of contractual trust. (We note, also, that Hawley considers and rejects as number of different putative analyses of contractual trust, and Tallant builds upon this to provide his own. We don't walk through all of the various competing analyses and objections, but do recommend them to the interested reader.) So, here is our thought. Mayer et al are claiming to give an account of trust. Our question: which kind? It is not trustworthiness that Mayer et al are giving an account of, nor is it the attitude of trust or contractual trust. What, then, are Mayer et al giving an account of? We do not know. Our speculation - though it is nothing more than that - is that Mayer et al are running together several different concepts, thereby giving an account of none. From all of this we learn that a very prominent account of trust, drawn from the business and management literature, is one that should be rejected.

\section{Other Options}

Mayer et al's analysis of trust is not the only option; we do not claim that it is. Our claim in section 3 of the paper is simply that it is prominent and widely adopted. Nonetheless, there are other accounts of trust given in the business oriented literature. Do these fare any better? 
We wish to be cautious. We do not want to claim that all definitions of trust that circulate within the theoretical end of the business literature are in bad shape. Such an analysis is beyond the scope of this paper. Nonetheless, we do want to consider what we take to be other key accounts. We will demonstrate that these, too, suffer from problems.

For instance, Dibben (2000: 12), having surveyed a range of definitions of trust (including that offered by Mayer et al.; it is worth noting that Dibben comes to a similar position to Mayer et al), offers the view that:

These definitions allow us to surmise that trust concerns a positive expectation regarding the behaviour of somebody or something in a situation which entails risk to the trusting party, this is therefore the description of the phenomenon that is adopted for the work reported in the following pages

There is a preliminary, easily solvable worry: as stated, this is not a definition of trust. Rather, this tells us what trust concerns. And many things may concern a positive expectation regarding the behavior of somebody or something. If we are to treat this as a definition of trust we should likely say something a little more precise, such as:

Trust is a positive expectation regarding the behavior of somebody or something in a situation which entails risk to the trusting party.

This kind of definition would look to be a definition of trusting to - of contractual trust. Trusting someone to perform some action is a positive expectation regarding the behavior of somebody or something in a situation which entails risk to the trusting party. The trouble, however, is that this definition is prone to counterexamples, very familiar within the philosophical literature. Indeed, we think that the lunch-bringer case we discussed in section 3.1 will do the job. In this imagined case, Hawley has positive expectations regarding the behavior of another party (the regular lunch-bringer) in a situation which entails risk to Hawley (she may go without food that day). Dibben's analysis would wrongly treat the lunch-bringer case as a case of trust. Other, similar cases are easy to construct. So, again, we have reason to reject Dibben's account.

Other, very similar remarks go for Rousseau et al. (1998), who define trust saying "Trust is a psychological state comprising the intention to accept vulnerability based upon positive expectations of the intentions or behavior of another" (1998: 395). Again, if we make ourselves vulnerable to hunger by placing positive expectations on the lunch-bringer then the analysis wrongly predicts that we have an instance of trust.

Equally, Möllering (2001) conceptualizes trust as a 'mental process of three elements': expectation, interpretation and suspension. ${ }^{6}$ Each term requires explanation. Expectation is the outcome. An outcome can either be favourable (in which case we have an instance of trust) or unfavourable (in which case we have an instance of distrust). Interpretation is the 'experiencing of reality that provides "good reasons"' (2001: 403) - as he calls them, 'the bases' - for

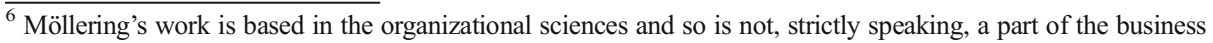
literature. Nonetheless, we consider it here because it has to at least some extent informed and influenced various parts of that literature. See, for instance, Mouzas et al. (2007: 1019), De Jong and Elfring (2010: 536), Sørensen, Hasle and Pejtersen (2011: 405), Dowell, Morrison and Heffernan (2015: 120) and Latusek and Vlaar (2018: 12). We note that in these discussions Möllering's work is not treated as the object of discussion, but built into a part of the theoretical background account of trust that the authors adopt.
} 
trusting. Thus we have the reasons, or bases, for trusting, and we have the expectation, and if that is favourable, then that is an instance of trust. However, because the link between bases of trust (/the reasons for trusting) and expectations (whether one does indeed trust) can be weak, suspension - a leap of faith - is the added element that allows for trust to take place.

Möllering's notion may be seen more clearly through an example. Suppose that we have reason to trust a corporation: they have provided us with adequate service over the years. Still, that need not lead to our trusting them; it need not lead to that positive outcome. We may recognise that the company has performed well and still have our doubts. Perhaps they may change how they function. Perhaps moves are afoot in the relevant market that worry us, and cause us to doubt that their current practices are adequate. To move from reasons to trust, we require a leap of faith — a 'suspension'.

Once again, though, we think that Hawley's case of the lunch-bringer causes problems. Hawley has reasons to think that the lunch bringer will bring enough lunch for her to eat the left-overs. Hawley has a positive expectation that they will bring additional lunch and, further, may take a leap of faith; not only does Hawley have reason to think that the regular lunch bringer will provide, via a leap of faith she forms the positive expectation that they will. That should suffice for trust, given Möllering's account. But still, and as before, this does not seem to be a case of trust. For, once again, there is no sense in which the lunch-bringer could be thought to have behaved improperly towards Hawley or to owe her an apology.

\section{Long and Sitkin}

So, we think that there is much conceptual work to be done within the business literature. However, we also not the first to note that there are challenges. Long and Sitkin (2018) do a superb job of providing a literature review of trust in the business literature.

Long and Sitkin do not draw the distinctions between trust, trusting to, mere reliance, and so on. Nonetheless we think that they do bring to light some interesting distinctions and challenges for future work. For instance,

research focused on trustors routinely leaves open questions about exactly who is conducting the attributional processes that lead to trust development, leaving readers to deduce for themselves whether these attributional processes are being conducted by an organization, an individual, a collection of individuals, or some relevant combination of these evaluators. (Long and Sitkin 2018: 730)

We agree and we commend them for their arguments.

But we also call for more conceptual work, for consideration of those kinds of trust that we distinguished in the opening section of this paper (and that are not discussed by Long and Sitkin). We also think that some of the other notions that are discussed by Long and Sitkin require further interrogation.

Long and Sitkin (2018: 73) rightly draw out a distinction often made in the business literature between competence based trust and good-will based trust. As they explain:

Subordinates exhibit competence-based trust when they observe their managers displaying expertise and developed capacities for performing critical cognitive or technical tasks. Alternatively, goodwill-based trust occurs when subordinates observe 
their managers exhibiting ideas, values, character traits, and behaviors that suggest that subordinate interests are being recognized, protected, and promoted by their managers.

This differentiation can be expressed thus:

Trust may concern a partner's ability to perform according to agreements (competence trust), or his intentions to do so (goodwill trust)' Noteboom (1996: 990),

Even here, though, we think that there are further conceptual challenges; ones that Long and Sitkin do not bring out (alongside some others that they do bring out—and, again, we applaud them for so-doing).

We need to distinguish two claims we might make about goodwill trust and competence trust. Is the distinction conceptual or is it causal? That is, is the claim that there is a distinctive kind of trust that consists in believing that someone we trust has goodwill towards us, and that there is another kind of trust that consists in believing that someone is competent with respect to the task? Or, instead, is the claim that in any instance of trust what we have is simply trust, but that it can be brought about by different routes: belief in the goodwill of a fellow agent, or belief in their competence? If the latter, we may then return to our original questions: are these to be thought of as instances of general trust, contractual trust, mere reliance?

We think that the quotation from Long and Sitkin, given just a moment ago, is most obviously read as a causal version of the competence based view. Their claim is that '[s]ubordinates exhibit competence-based trust when they observe their managers displaying expertise and developed capacities for performing critical cognitive or technical tasks.' This seems to us a claim about when agents exhibit competence trust - what brings it about - rather than what it is.

If we follow that reading, then competence-based trust is not a distinctive kind of trust at all. So-far, so good. But we must then ask what kind of trust it is that has been thus caused? Do we have here the attitude of trust, contractual trust or mere reliance? We thus find ourselves back with the philosophical question we raised in the opening sections of the paper.

In contrast, there is another reading available. Barber (1983: 14), for instance, defines competence trust as 'the expectation of technically competent role performance'. Our reading of Barber, then, is that this is definitional; a claim is being made about competence trust is.

If our reading of Barber is correct, then we might have a distinctive kind of trust on our hands: competence-based trust. But, if that is right, then it seems to generate some implausible results. For instance, if all we must do to trust an individual in this sense is expect of them technically competent role performance, then it seems that we get a whole host of wrong results. For example, the authors work in universities. We expect technically competent role performance form all of our colleagues, including those we have not met. But we do not trust them all to produce such work - especially not the ones we have not met. That being so, we do not think that this reading of Barber can be quite right; we do not think that there is a distinctive kind of trust - competence-based trust - that satisfies the given definition.

We think, then, that Long and Sitkin are right to treat good-will trust and competence trust as causal routes to creating trust, not as a distinctive kind of trust. But then we return to our earlier refrain: trust of which kind? Thus, whilst we find much to like in Long and Sitkin's paper, we think that further clarificatory work is required.

As promised, we now wish to turn our attention to that which flows from this. The theoretical question, in isolation, is of only so much import - even if trust is, as we suggest, 
a concept central to our moral and ethical theorising. In particular, we want to turn our attention to various pieces of empirical research that have been carried out, and to demonstrate that what is being investigated is not trust at all, despite that being the claim of the research. That being so, swathes of empirical research from the business literature is in need of revision and/or refinement.

\section{Empirical Work}

Toward the applied end of the literature, there is understandable commercial interest in locating factors that lead to the development of trust. In order to identify those factors, it is essential to clearly distinguish trust itself from the factors that lead to trust formation. As can then be appreciated, it is essential that we do not conflate trust with those factors that lead to trust.

To give but one example of how this can manifest in problematic ways, let us explore work carried out by Bart (et al) who examined the different kinds of drivers for (or antecedents of) trust in online contexts. Having first identified various different expected drivers of trust, they then set about testing their hypotheses, that said drivers would lead to trust, by gauging how participants in their study responded to the following questions (Bart (et al): 2005, 150):

117. This site appears to be more trustworthy than other sites I have visited.

123. The site represents a company or organisation that will deliver on promises made.

124. My overall trust in this site is.

125. My overall believability of the information in this site is.

126. My overall confidence in the recommendations in this site is.

Now, clearly, 117 and 124 are asking direct questions about trust (though more of this in just a moment), but 123, 125 and 126 are not explicitly about trust. Nonetheless, answers to all of these questions were treated as generating a measure of trust. That is, if someone responded to questions 123,125 , and 126 signaling that they thought the company would deliver, was believable, and that they were confident in it, that is taken as a direct measure of their trust in the company. Unless those are features of trust itself, however, that cannot be quite right. So, at the very least, Bart (et al) owe us some further justification for thinking that answers to these questions will demonstrate trust of some kind - they also need to tell us which kind of trust.

And, problematically, it seems that the remaining questions are not all directed at the same kind of trust, and not all are about trust. 117 asks about the appearance of trustworthiness. Well and good. If a respondent indicates that a website appears trustworthy, that is a pretty clear measure of whether or not they think that the website $i$ s trustworthy. We could infer something similar about a positive response to 123 .

But we cannot do this in the case of 124. This question is asking about 'trust in', the site; not whether the site is trustworthy (and something can be worthy of trust without our giving it - perhaps due to excessive nervousness or unreasonable concerns about risk). Similarly, 'believability', which is what 125 asks about, is not obviously a constituent of any kind of trust. A con artist is very believable, so are simple narratives. That does not mean that they are trustworthy. Perhaps 'trust in' could be thought of as a bit like two-placed trust. Someone who trusts a site, has trust in it. Or perhaps the idea could be that 'trust in' is a form of contractual trust: 'I trust the site to tell me the truth'. We are not sure. What matters, though, is that this 'trust in' is not measuring the same thing as that which is measured by asking whether or not a 
customer regards someone as trustworthy; trustworthiness is one thing, contractual trust another. If we run the two together, as do Bart (et al), then we are simply muddying conceptual waters.

126 generates a different problem for it asks, not about trust, but about confidence. Confidence is not trust. It may lead to it, but it is distinct. For instance, neither author would trust a very successful serial killer, someone who has managed to kill many, many people. We do not think it sensible to do so; we would recommend the reader to avoid doing so, as well. We would, however, have confidence in a successful serial killer. Other cases are easy. It is easy to imagine that someone who was especially disturbed by Starbucks' position on tax in the UK might not trust them. However, they might still have every confidence in the company; they might invest in them, recommend them for a 'solid' cup of coffee in a pinch, and so onbut that is not to say that they trust them.

What we are left with, then, is a set of questions that are not asking about a single, choate notion, but, at best, a cluster of concepts, some of which might be said to constitute $a$ form of trust, some of which might constitute a different notion of trust, and yet others of which might be about the precursors to some kind of trust. If we wish to have robust empirical findings, about $\mathrm{x}$, for any $\mathrm{x}$, then we must ensure that we are measuring $\mathrm{x}$; not that we are measuring $\mathrm{x}, \mathrm{y}$ and the features that might lead to them. This kind of empirical work, then, is in need of refinement.

To give a second example, consider Aghion et al. (2010). The chief focus of their paper is the connection between distrust (generally, and in business and management) and heightened governmental regulation. Focusing on distrust, specifically, they use a number of measures to determine the level of trust that individuals may have in a government, business, or similar, using this as a basis to then consider changes in the level of governmental regulation.

As they put the point: "In a simple model explaining this correlation, distrust creates public demand for regulation, whereas regulation in turn discourages formation of trust, leading to multiple equilibria."

But, at least some of these measures upon which they rely seem focused on factors other than distrust itself. Drawing on the World Values Survey (WVS), they explain that their methodology largely proceeds as follows.

We use data on distrust from the World Values Survey(WVS). The WVS is an international social survey consisting of four main waves, 1981-1984, 1990-93, 1995, and 1999-2003... This survey provides a range of indicators of distrust in others, in markets, and in institutions for a large sample of countries. (Aghion et al. 2010: 1018, our italics)

What is not clear, however, is how much information they actually gather about distrust. Or, to be more precise: there is a concern that some of the data that they treat as being about distrust is not, or may not be, about distrust.

Here is how they describe some of the data that they draw upon (Aghion et al. 2010: 1019):

WVS also asks the following questions: "Do you have a lot of confidence, quite a lot of confidence, not very much confidence, no confidence at all in the following: Major companies? Civil servants?" The answers range from 1 for a lot of confidence, 
through 2 for quite a lot of confidence, 3 for a little confidence, and 4 for no confidence. We create a dummy equal to 1 if the respondent chooses the answer no confidence, and zero otherwise. We thus have two dummy variables, distrust in companies and distrust in civil servants.

As above, it is far from clear, however, how to associate a lack of confidence in an organisation with trust or distrust in that organisation.

We should also note that a lack of confidence in a company does not entail a distrust of that company. There are many companies that we have never heard of and in which we thereby have no confidence at all. This does not mean that we distrust them. It means that we do not trust them; as above, an important distinction.

There are then two important points that need noting. First, we have, throughout this paper, been operating with three different kinds of trust: an attitude, a claiming about trustworthiness, and a form of what we are calling 'contractual' trust. Now, what Aghion et al are concerning themselves with are not quite cases like that. That is, they are not considering or asking about cases where one agent can be said to trust another. Rather, as is clear from their question, they are asking questions of an agent, about whether or not they have confidence in major companies (plural); or, whether they have confidence in civil servants (plural). This is important.

What this brings out nicely is that a number of these forms of trust can be one: one; one: many and many: many. For instance, though we introduced contractual trust as a relation between one agent and another, we can also speak of agents trusting major companies to carry out particular actions, or, indeed, of one group of major companies trusting another to carry out particular actions. Despite the fact that forms of trust have this feature, there is no compelling reason to think that these demark further kinds of trust (simply: contractual trust can be one:one; one:many; many: many). ${ }^{7}$

Second, there remains a question as to which kind of distrust Aghion et al take themselves to be reporting on. It is prima facie tempting to think that they must be thinking of simple twoplaced distrust of the form ' $\mathrm{x}$ distrusts $\mathrm{y}$ ', since the data that they get is simply whether or not respondents have confidence in a company or in civil servants. But, if that is right, then another problem drifts into view. For the reasons given in discussion of Bart et al, we cannot treat confidence as one-placed trust.

What, then, if we treat 'confidence in' not as trust, but as contractual trust. Does that help Aghion et al? We do not think so. To illustrate how confidence in $\mathrm{x}$ to $\varphi$ differs from trust that $\mathrm{x}$ will $\varphi$ (in other words, how x's confidence in $\mathrm{y}$ to $\mathrm{F}$ comes apart from the contractual trust that $\mathrm{x}$ has that $\mathrm{y}$ will $\mathrm{F}$ ) consider the relationship that a fan may have with their preferred team in a sport.

Here is an illustrative example. Sam can have great confidence in their preferred football team to win a match, without trusting them to do so. To see this, note that if Sam's team loses, though Sam may be dissatisfied, this need not require that Sam blame them, morally, or suggest that they have particular moral failings. Sam can simply concede that, on the day, the other team played better. In this case, we think, Sam had confidence in his team to win; he did not trust them to win. That being so, x's confidence in y to $\varphi$ is not identical to x's trust that $\mathrm{y}$ will $\varphi$.

\footnotetext{
$\overline{{ }^{7} \text { For an account of how this might }}$ go in the case where an individual agent trusts a collection of agents (or a collection of a collection of agents), see Hawley (2017).
} 
If we are right about all of this, then Aghion et al cannot draw the kinds of conclusion that they wish to. That is, to give an example:

Figure I illustrates the strong positive correlation between the regulation of entry as measured by the $(\ln )$ number of steps to open a business, and the country level of distrust. High-trusting countries such as Nordic and Anglo-Saxon countries impose very few controls on opening a business, whereas low-trusting countries, typically Mediterranean, Latin-American, and African countries, impose heavy regulations. One-third of the cross-country variation in the regulation of entry is explained by distrust. Figure II shows a strong positive correlation between the rigidity of employment contracts and distrust. (Aghion et al. 2010: 1019)

If confidence and trust come apart, and we think that we have shown that they can and do, then much more work would need to be done to justify this conclusion, that there is a correlation between regulation and distrust. To be sure, we may claim that there is a correlation between confidence and regulation, but that is not the same thing at all.

Thus, although it might be reasonable to suppose that, in some contexts, the phenomena of confidence and trust will correlate, and certainly reasonable to think that a lack of confidence may lead to distrust in certain contexts, it is far from clear that they have to. Thus, it is far from clear that we are being presented with a reliable measure of distrust. That being so, we can see that the conceptual question of what distrust is threatens to undermine the findings of Aghion et al.

$\mathrm{Be}$ that as it may, there is an interesting question here of how to understand trust in regulation, or the rule of law. After all, in the cases they are discussing, Aghion et al are concerned with questions around regulation.

Tentatively, we think that this can be understood in terms of contractual trust in key institutions. That is, to say that we trust in regulation (or law), $\mathrm{R}$, in country, $\mathrm{C}$, is to say that we trust the institutions in $\mathrm{C}$ that are charged with upholding $\mathrm{R}$, to do so in a way that is fair and appropriate. Of course, that is conjecture and would require further analysis. Nonetheless, it does appear plausible. If the institutions in a given country do not uphold the regulations in a way that is fair and appropriate, then we do not think that agents will be likely regard trust local regulation. And, of course, if we are right about the analysis then it would provide further support for our claim that Aghion et al. cannot treat confidence as the same as (the relevant kind of) trust, for, as above, what we would have in the case of putting trust in regulation would be contractually trusting relevant institutions to uphold regulation in a way that is both fair and appropriate. Clearly, that can come apart from confidence.

The general claim that research about how to generate trust, how to generate a sense of trustworthiness, and similar, may need to pay attention to the clarifications and refinements offered by philosophy, is important. Good empirical work into what will produce trust cannot take place without a precise conception of trust, and the various kinds of trust, at its core. We could work our way through other papers, but we shall rest here with the general point already made.

\section{Why Does this Matter Outside Academia?}

Away from the academic literature, it is worth noting just briefly how some of the same kinds of issue come up in the commercial sector itself. There, as with the business literature, alleged empirical findings purporting to show some fact about trust in fact show no such thing. 
For instance, Edelman, who self-describe as the world's largest PR firm, carry out an annual trust survey. In their own words:

'Edelman's Trust Barometer® is an annual global trust survey which measures attitudes about the state of trust in business, government, NGOs and the media. Now in its 16th year, the Trust Barometer, powered by Edelman Berland, surveys over 33,000 respondents from 28 different countries.'

Especially interesting for our purposes is the way in which some of the findings are reported. In particular, Edelman report that within UK politics, '[d]istrust is now the default position'.

However, we worry that this reporting of the data over-estimates what has been shown. The first crucial conceptual point that we need to draw upon here is that not trusting is distinct from distrusting. As we saw above, not trusting $x$ is fundamentally different in kind from distrusting $x$. This matters, in this case, because the question Edelman ask concerns not trusting; they do not ask about distrusting.

They ask respondents:

Below is a list of institutions. For each one, please indicate how much you trust that institution to do what is right using a nine-point scale, where one means that you "do not trust them at all" and nine means that you "trust them a great deal". 9

Not trusting a company is not the same as distrusting a company. To again call to mind the earlier example, we would not trust (at all) someone that we meet for the first time. Nor would we distrust them (at all). We simply would not trust them. Edelman are asking respondents about cases where they do not trust. They cannot, then, sensibly draw clear conclusions about whether respondents distrust.

Of course, it is an open possibility that respondents took Edelman to mean that the scale runs from trust at one end, to distrust at the other. But, as we have shown earlier in the paper, there is clear conceptual water between a lack of trust and distrust. The question asked by Edelman simply is not perspicuous enough for us to have confidence in that judgement, and as such the claim that in British politics, '[d]istrust is now the default position' simply cannot be sustained. This is hardly trivial, either. With a client base including a range of multi-national corporations, as well as University and City connections, the work that Edelman does quite plausibly has real-world consequences. ${ }^{10}$ If they are to produce the right answers, they must ask the right questions.

Second, it is also worth pausing to reflect upon the kind of trust that Edelman are exploring in their questions and the way that is being reported. As noted but a moment ago, the question Edelman are asking concerns a very particular structured kind of trust. To repeat: 'please indicate how much you trust that institution to do what is right'. This is contractual trust. They are asking a question of the form: 'do you trust $\mathrm{x}$ to $\varphi$ ?' But what they are reporting, is that the

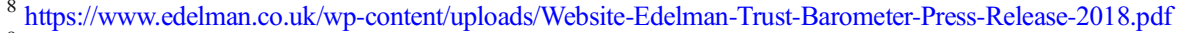

${ }^{9} \mathrm{https} / / / w w w . s l i d e s h a r e . n e t / E d e l m a n \_U K /$ edelman-trust-barometer-2018-uk-results/1

${ }^{10} \mathrm{~A}$ representative list appears here: https://www.edelman.co.uk/work/ The survey is described by the British newspaper The Independent as 'the largest and longest running study of trust in the world'. http://www. independent.co.uk/news/uk/home-news/edelman-trust-barometer-social-media-trust-declined-a8170816.html By any estimation, the barometer is an extremely significant tool, but one that seems to not have received critical analysis, to date.
} 
British people 'distrust the Government'. This marks a slide. They begin with three-placed trust ('please indicate how much you trust that institution to do what is right') but draw a conclusion about one-placed trust (people distrust the government). Whilst the conclusion may be true, the question that they have asked does not obviously allow us to draw that conclusion. ${ }^{11}$ The point that we are making here is, of course, structurally similar to the point we made about the empirical literature on trust. If we wish to know about where some concept $\mathrm{x}$ is being deployed (trust, contractual trust, trustworthiness, distrust, etc.), we must ask questions about x; we cannot ask about concepts that are similar to $\mathrm{x}$, though distinct from it, and then draw conclusions about $\mathrm{x}$. Thus, if Edelman wish to report about distrust, then they must ask about it.

Moving away from the specifics of the Edelman case, we should pause. We have focused, here, on teasing apart a series of related concepts: contractual trust, trustworthiness, trust, confidence, and so on. Suppose that everything we have said so far is correct, Still, there might be a temptation to ask 'so what?' After all, what is underlying many discussions of trust and cognate concepts in this literature is the question of whether or not one agent will or should do business with another. And though, conceptually we might be right, that trust, confidence and the rest all come apart, still: might it not be the case that it does not much matter to agents whether they have trust in a potential partner, or confidence, or contractual trust that they will perform some specific action? At the end of all of this, how do we know that it matters whether what is present between agents is trust, one of the other concepts described, or simply all of them? To put the same point a slightly different way: is not the point of the empirical literature to try and work out when folks will engage with transactional relationships with one another? If so, then to what extent does the conceptual analysis really matter?

At this point, we submit, we do not know - and it is here that we wish to pivot back in the direction of the empirical literature. The empirical literature can tell us what is required in order to facilitate transactional relationships. In turn, that can drive an improvement to transactional relationships. However, in order to properly frame the empirical questions, we must ask about the right concepts. Perhaps contractual trust is the overriding factor in transactional relationships. Perhaps it is not. Perhaps the general attitude of trust is what is key. Or perhaps what matters is the general attitude of trust when it is coupled to confidence. Or perhaps it does not matter at all so long as we have one of the above. The point is that we do not know the answer for the empirical questions have not been properly framed by the requisite conceptual workat least, for much of the literature we believe that this is so. As above, we cannot be sure that, somewhere, there is not a pocket of business literature that is doing extremely robust conceptual work. However, at least so far as we can see, at the moment there are significant parts of the business literature is not quite operating with the required conceptual clarity.

So, suppose confidence is a reasonable proxy for trust. And suppose, too, that our general empirical literature can predict, with some confidence, when one party will engage in transactions with another. Even then, what we will not know, unless we examine the concept of trust, is whether those transactional relationships can be improved by improving and enhancing some kind of trust. After all, if trust is a driver for transactional relationships, it is entirely possible that we may improve still further our capacity to predict when transactional relationships will develop if we can get clarity on the nature of trust, and then engage in careful empirical analysis. Certainly,

\footnotetext{
${ }^{11}$ None of this is to suggest that Edleman are doing bad work. The actual questions asked and the data delivered are extremely useful. The simple point remains that, at least given the data that they have, the conclusions being drawn are being overstated. Given their influencing power, this matters.
} 
without first doing the conceptual work, and then carrying out careful empirical work, we will not be able to determine whether improvements can be driven in this way.

\section{Conclusions}

The basic point that precision and clarity matter in inquiry is bordering on the banal. The observation that this precision and clarity is at least a little lacking in our academic and commercial discussions of trust is not. The focus of this paper has been making the latter point. If we wish to have a proper theoretical, empirical and commercial grasp of the role that trust plays in our lives, we must deploy greater precision and clarity in the questions we ask and in the conclusions we drawn. With trust playing such an important role in our moral deliberations, we take this to be a highly significant conclusion. We must do better.

\section{Compliance with Ethical Standards}

Conflict of Interest All authors' declare that they have no conflict of interest.

Ethical Approval This article does not contain any studies with human participants or animals performed by any of the authors.

Open Access This article is distributed under the terms of the Creative Commons Attribution 4.0 International License (http://creativecommons.org/licenses/by/4.0/), which permits unrestricted use, distribution, and reproduction in any medium, provided you give appropriate credit to the original author(s) and the source, provide a link to the Creative Commons license, and indicate if changes were made.

Publisher's Note Springer Nature remains neutral with regard to jurisdictional claims in published maps and institutional affiliations.

\section{References}

Abosag, I., and J.-W. Lee. 2013. The formation of trust and commitment in business relationships in the Middle East: Understanding et-Moone relationships. International Business Review 22: 602-614.

Aghion, P., Y. Algan, and A. Shleifer. 2010. Regulation and distrust. The Quarterly Journal of Economics 125: 1015-1049.

Allen, M.R., J.K. Adomdza, and M.H. Meyer. 2015. Managing for innovation: Managerial control and employee level outcomes. Journal of Business Research 68: 371-379.

Barber, B. 1983. The Logic and Limits of Trust. New Brunswick: Rutgers University Press.

Bart, Y., V. Shankar, F. Sultan, and G. Urbab. 2005. Are the drivers and role of online trust the same for all web sites and consumers? A large-scale exploratory empirical study. Journal of Marketing 69: 133-152.

Brattström, A., H. Löfsten, and A. Richtnér. 2012. Creativity, trust and systematic processes in product development. Research Policy 41: 743-755.

Colquitt, J.A., and J.B. Rodell. 2011. Justice, trust and trustworthiness: A longitudinal analysis integrating three theoretical perspectives. Academy of Management Journal 54 (6): 1183-1206.

De Jong, B.A., and T. Elfring. 2010. How does trust affect the performance of ongoing teams? The mediating role of reflexivity, Monitorting, and effort. Academy of Management Journal 53: 535-549.

Dibben, M. 2000. Exploring Interpersonal Trust in the Entrepreneurial Venture. Basingstoke: Macmillan Press.

Dowell, D., M. Morrison, and T. Heffernan. 2015. The changing importance of affective trust and cognitive trust across the relationship lifecycle: a study of business-to-business relationships. Industrial Marketing Management 44: 119-130. 
Fang, Yulin, Israr Qureshi, Heshan Sun, Patrick McCole, Elaine Ramsey, and Kai H. Lim. 2014. Trust, satisfaction, and online repurchase intention. MIS Quarterly 38 (2): 407-427.

Faulkner, P. 2015. The attitude of trust is basic. Analysis 75: 424 429.

Fletcher, R., and P. Sora. 2017. The impact of trust in the news media on online news consumption and participation. Digital Journalism 5 (10): 1281-1299. https://doi.org/10.1080/21670811.2017.1279979.

Hardin, R. 2002. Trust and Trustworthiness. Russell Sage Foundation.

Hassanein, K., and M. Head. 2007. Manipulating perceived social presence through the web interface and its impact on attitude towards online shopping. International Journal of Human Computer Studies 65: 689-708.

Hawley, K. 2014. Trust, distrust and commitment. Nous 48: 1-20.

Hawley, K. 2017. Trustworthy Groups and Organisations. In New Philosophical Perspectives on Trust, ed. P. Fauklner and T. Simpson. Oxford: OUP.

Hwee Hoon, T., and A.K. Lim. 2009. Trust in coworkers and trust in organizations. The Journal of Psychology 143 (1): 45-66. https://doi.org/10.3200/JRLP.143.1.45-66.

Jackson, F. 1999. From Ethics to Metaphysics: a Defence of Conceptual Analysis. Oxford: OUP.

Jones, J. 2012. Trustworthiness. Ethics 123: 61-85.

Kim, D.J., D.L. Ferrin, and H.R. Rao. 2008. A trust-based consumer decision-making model in electronic commerce: The role of trust, perceived risk, and their antecedents. Decision Support Systems 44: 544-564.

Lankton, N., and D. McKnight H. 2012. Incorporating trust-in-technology into Expectatio disconfirmation theory. Journal of Strategic Information Systems 23: 128-114.

Latusek, D., and P.W.L. Vlaar. 2018. Uncertainty in interorganizational collaboration and the dynamics of trust: A qualitative study. European Management Journal 36: 12-27.

Li, Y.-M., and Y.-S. Yung-Shao Yeh. 2010. Increasing trust in mobile commerce through design aesthetics. Computers in Human Behavior 26: 673-684.

Lin, H.-F. 2011. An empirical investigation of mobile banking adoption: The effect of innovation attributes and knowledge-based trust. International Journal of Information Management 31: 252-260.

Long, Chris P., and Sim B. Sitkin. 2018. Control-trust dynamics in organizations: identifying shared perspectives and charting conceptual fault lines. Academy of Management Annals 12 (2): 725751. https://doi.org/10.5465 /annals.2016.0055.

Mayer, Roger C., James H. Davis, and F. David Schoorman. 1995. An integrative model of organizational trust. The Academy of Management Review 20: 709-734.

Möllering, G. 2001. The nature of trust: From Georg Simmel to a theory of expectation, interpretation and suspension. Sociology 35 (2): 403-420.

Mouzas, S., S. Henneberg, and P. NaudS. 2007. Trust and reliance in business relationships. European Journal of Marketing 41: 1016-1032.

Nooteboom, B. 1996. Trust, opportunism and governance: A process and control model. Organization Studies 17 (6): 985-1010.

Rousseau, Denise M., Sim B. Sitkin, Ronald S. Burt, and Colin Camerer. 1998. Not so different after all: a crossdiscipline view of trust. Academy of Management Review 23 (3): 393-404. https://doi.org/10.5465 /amr.1998.926617.

Sørensen, O.H., P. Hasle, and J.H. Pejtersen. 2011. Trust relations in management of change. Scandanavian Journal of Management 27: 405-417.

Steup, M. (2018). 'Epistemology', The Stanford Encyclopedia of Philosophy (summer 2018 edition), Edward N. Zalta (ed.), forthcoming URL $=<$ https:/plato.stanford.edu/archives/sum2018/entries/epistemology/ $>$.

Tallant, J. 2017. Commitment in cases of trust and distrust. Thought 6: 261-267.

Vanhala, M., P. Heilmann, and H. Salminen. 2016. Organizational trust dimensions as antecedents of organizational commitment. Knowledge and Process Management 23 (1): 46-61.

Jonathan Tallant is Professor of Philosophy at the University of Nottingham.

Donatella Donati a Philosophy Postdoc Fellow at the University of L'Aquil. 